\title{
Narrar la(s) guerra(s) con las voces de mujeres: memoria, género y emociones. Una mirada comparada ${ }^{1}$
}

\author{
War through women's voices: \\ memory, gender and emotions. A comparative gaze
}

\author{
Judyta Wachowska \\ Uniwersytet im. Adama Mickiewicza w Poznaniu, Instytut Filologii Romańskiej \\ Zakład Literatury Hiszpańskiej i Iberoamerykańskiej \\ wachita@amu.edu.pl
}

\begin{abstract}
The paper undertakes a comparative analysis of three texts: War's Unwomanly Face by Svetlana Alexievich, the novel The Sleeping Voice by Dulce Chacón, and a testimony about women's activism, resistance and imprisonment during the Francoist regime edited by Tomasa Cuevas. The aim of the study is to examine the problems of feminine authors' narratives being excluded from official archives of memory, as well as emotions. The issues are considered in two different political contexts which, nevertheless, reveal quite similar mechanisms of an organization using hegemonic discourses of power.
\end{abstract}

Keywords: feminine authors' narratives of the war, $2^{\text {nd }}$ World War, Spanish Civil War, gender, women's memory, emotions

No estaría mal escribir un libro sobre la guerra que provocara náuseas, que lograra que la sola idea de la guerra diera asco. Que pareciera de locos. Que hiciera vomitar a los generales....

(Alexiévich, 2015, pos. 179-180)

\footnotetext{
${ }^{1}$ Algunas de las tesis del presente artículo fueron presentadas por la autora en forma de comunicación oral "La prisión franquista tiene rostro de mujer. Emociones de los cuerpos en $\mathrm{La} \mathrm{voz}$ dormida (D. Chacón)”, durante el congreso "¿Corazón helado? Narradoras españolas contemporáneas desde la teoría de las emociones", organizado por el Instituto de Estudios Ibéricos e Iberoamericanos de la Universidad de Varsovia, en mayo de 2016.
} 
El premio Nobel de Literatura para Svetlana Alexiévich coincidió en España con la edición de La guerra no tiene rostro de mujer en que la autora narra unas historias de la Segunda Guerra Mundial y la posguerra a través de las voces de mujeres que, siendo periodista y reportera, había grabado en sus viajes por Rusia, sacándolas de un largo silencio. Las mujeres entrevistadas son de la ex Unión Soviética, mayormente de la región de la Bielorrusia de hoy, y la mayoría de ellas participó de forma activa en la guerra contra el fascismo. En la introducción al texto, basada en sus apuntes para el libro, la autora hace una especie de declaración de principios de su poética. Explica que gracias a su maestro Alés (Aleksander) Adamóvich $^{2}$ entendió que el género literario que le interesaba escribir era "la novela $[\ldots]$ construida a partir de las voces de la vida diaria" (Alexiévich, 2015, pos. 62). Arguye sobre todo la necesidad de narrar la guerra desde la óptica de las mujeres, lo cual en sus anteriores intentos se convertía en un obstáculo censor tanto por parte de las redacciones de periódicos como de las editoriales por ser una perspectiva incómoda y proponer las historias que parecían "no de «esta guerra»" (Ostałowska, 2011, par. 8):

El manuscrito lleva mucho tiempo sobre la mesa... Llevo dos años recibiendo cartas de rechazo de las editoriales. Las revistas guardan silencio. El veredicto siempre es el mismo: es una guerra demasiado espantosa. El horror sobra. Sobra naturalismo. No se percibe el papel dominante y dirigente del Partido Comunista. En resumen [constata la autora], no es una guerra correcta... ¿Y cómo es entonces la correcta? - [se pregunta]- ¿Con los generales y el sabio generalísimo? ¿Sin la sangre y los parásitos? (Alexiévich, 2015, pos. 258-261)

El texto pertenece al género de reportaje literario, polifónico, aunque la misma autora lo denomina como novela de voces; vuelvo a citar: novela "construida a partir de las voces". La autora concede mucha atención a los valores de la oralidad en la escritura: "Textos. Textos. Los textos están en todas partes. En los apartamentos de la ciudad, en las casas del campo, en la calle, en el tren... Estoy escuchando... Cada vez me convierto más en una gran oreja, bien abierta, que escucha a otra persona.

\footnotetext{
${ }^{2}$ Aleksander (Alés) Adamóvich (1927-1994), de origen bielorruso, fue escritor, historiador y crítico de literatura, coautor de guiones fílmicos, profesor y miembro correspondiente de la Academia de Ciencias de Bielorrusia. Svetlana Alexiévich explica que, al repensar durante varios años el tema del libro (que además fue su primero), no encontraba la forma literaria a través de la cual pudiera estar segura de narrar las historias de las mujeres de la guerra, hasta que finalmente leyó uno de los libros de Adamóvich: "Estuve buscando... ¿Con qué palabras se puede transmitir lo que oigo? Yo buscaba un género que correspondiera a mi modo de ver el mundo, a mi mirada, a mi oído. Un día abrí el libro Ya iz ógnennoi derevni (Soy de la aldea en llamas), de A. Adamóvich, Y. Bril y V. Kolésnik. Solo una vez había experimentado una conmoción similar, fue al leer a Dostoievski. La forma del libro era poco convencional: la novela está construida a partir de las voces de la vida diaria. De lo que yo había oído en mi infancia, de lo que se escucha en la calle, en casa, en una cafetería, en un autobús. ¡Eso es! El círculo se había cerrado. Había encontrado lo que estaba buscando. Lo que presentía. Mi maestro es Alés Adamóvich..." (Alexiévich, 2015, pos. 59-64).
} 
«Leo» la voz” (Alexiévich, 2015, pos. 129-131). ${ }^{3}$ El género trabajado por Alexiévich en el ámbito de la literatura hispanoamericana recibe el nombre de crónicas y en inglés se llama non-fiction prose. Estas clasificaciones, que desconciertan o plantean problemas a los que investigamos los campos literarios, en el ámbito de la literatura española pueden sugerir, como creo, un parentesco con dos textos. De un lado, y sobre todo, con la obra magna y precursora de Tomasa Cuevas sobre la militancia, resistencia y la prisión femenina durante la Guerra Civil española y la dictadura franquista, reconocida por varias invesigadoras del tema bajo el rótulo de "testimonio colectivo" (Mangini, 1995, p. 112) o "testimonio de efecto coral" (Prieto, 2011, p. 166). De otro, podemos ampliar la comparación a La voz dormida, ${ }^{4}$ novela para la cual Dulce Chacón hizo un amplio trabajo documental recogiendo, como ha declarado en varias ocasiones, las voces de las mujeres que después de sufrir la guerra, al verse obligadas a guardar silencio sobre sus actividades en la resistencia antifranquista y la opresión sufrida por parte del Estado franquista, permanecieron “olvidadas entre olvidados" (Ramblado Minero, 2004-2005, cit. por Legott, 2015, p. 49) también durante largos años de la Transición democrática.

Aunque los mencionados textos provienen de diferentes geografías políticas y tradiciones literarias, comparten el mismo marco de la perspectiva de género e incorporan los temas del archivo oficial de memoria. La lectura comparada de los tres textos lleva a unas pistas que matizan la marginación y/o exclusión de las narraciones femeninas del archivo oficial memorístico con la óptica de emociones. El marco afectivo, que es interesante para la lectura de género $y$, de hecho, feminista, sobre unos acontecimientos traumáticos, se objetiva al analizar los textos no solo en pensar en mujeres sino desde el enunciado de la mujer. De este modo, los textos que aquí se analizan indican la ruptura y el desenmascaramiento del poder que ha marginalizado y/o exluido sus voces. El poder, a su vez, concierne tanto el discurso político-cultural como el discurso de la memoria, una memoria traumática en este caso. Tal y como ha observado K. Bojarska, el hecho de que algunas expe-

\footnotetext{
${ }^{3}$ También en el discurso Nobel, la autora bielorrusa volvió al tema: "Flaubert decía de sí que era hombre pluma, yo puedo decir de mí misma que soy persona oreja. Cuando paseo por la calle y capto palabras, frases, exclamaciones siempre pienso: cuántas novelas se desvanecen sin dejar huella en el abismo del tiempo. En la oscuridad. Hay una parte de la vida humana, la parte conversacional, que no se ha dejado conquistar por la literatura. Todavía no la hemos apreciado, no nos ha aturdido, ni encantado. No obstante, a mí me tiene sobrecogida y me ha convertido en su cautiva. Me encanta cuándo y cómo los seres humanos hablan. Amo cada voz humana, única e irrepetible. Es un gran amor mío, mi gran pasión" (Alexiévich, 2015, en línea; traducción mía del ruso).

${ }^{4}$ La contribución de las y los testigos de la historia narrada es apuntada al final de la novela en una larga lista (en forma de paratexto), como también mencionada en numerosas entrevistas que la autora extremeña concedió después de la publicación de la novela. Entre toda una variedad de investigaciones, la narración ha sido tildada de: "novela coral" (Ramos, 2012, p. 370), "hibridización de memorias" (Colmeiro, 2008), y la misma autora gracias al proceso de su trabajo fue considerada "testigo estético" (López de la Vieja, 2003, cit. por Servén Díez, 2015, p. 113).
} 
riencias históricas no hayan encontrado lugar en el archivo oficial del pasado nos deja información sobre todo acerca del poder que haya organizado este archivo así como de las estructuras del conocimiento que delimitan su comprensión (2015, p. 197). De hecho, creo también que esta perspectiva se relaciona con el famoso lema feminista de que "lo personal es político" (Hanish, 1969, en línea) debido a que las emociones pueden partir y/o desembocar en lo personal, pero no por ello son privadas o, por lo menos, no lo son del todo. Siguiendo a Bojarska, consideraré esta estrategia analítica como una "ruptura y disturbio afectivos" en el archivo de las formas hegemónicas de sentir, expresar y vivir la historia (2015, p. 198), que en el caso de los relatos femeninos aquí analizados se relacionaría con el poder sobre el discurso histórico y sobre la memoria traumática de varias experiencias bélicas: la Guerra Civil y posguerra española, la Segunda Guerra Mundial y la posguerra en la URSS.

Este modelo de lectura se arraiga también en Sara Ahmed (2015). Al desarrollar su investigación acerca de las políticas culturales de emociones, Ahmed subraya el hecho de que las emociones tienen carácter individual y colectivo, y que sufren la "socialidad": al mismo tiempo que se exteriorizan trabajando "de adentro hacia afuera", también se interiorizan "de afuera hacia adentro" (Ahmed, 2015, p. 31). Las emociones no solo quedan fijadas en los cuerpos, sino que circulan, se mueven y pasan entre los cuerpos, de modo que estos adquieren una forma (molde) gracias al contacto con las emociones y con los demás. El cómo funcionan las emociones influye en el proceso de moldear los cuerpos individuales y colectivos (Ahmed, 2005 , p. 19). De ahí que los disturbios y rupturas afectivos que observo en los textos analizados señalan los dos movimientos de las emociones. Al indicar un diálogo cultural-político (no-intencional) entre las formas hegemónicas del poder que, no obstante, están formadas por unos archivos diferentes, fijan y hacen circular un repertorio de emociones colectivas bastante similares, sobre todo el dolor y el miedo. En la lectura que voy a realizar, trataré las mencionadas narraciones como textos de cultura, según propone J. Labanyi (2010, p. 231). Sin embargo, no es mi intención analizar cómo las emociones afectan la estructura narrativa de los relatos femeninos de la guerra y de la posguerra, sino señalar cómo estos relatos que operan con y a través de las emociones, influyen en las dinámicas del poder, es decir, el poder sobre el discurso de las ("grandes") narraciones.

La lectura comparada que realizo es originada por el tema del presente número monográfico orientado a las poéticas y políticas de la memoria. Creo que los lectores y las lectoras hispanohablantes están más familiarizados con los textos de las mencionadas autoras españolas; por ende, el punto de partida en mis indagaciones se centrará en la obra de la escritora bielorrusa, ${ }^{5}$ a cuya lectura iré remitiendo los contextos ocasionados por la lectura de Tomasa Cuevas y de Dulce Chacón.

\footnotetext{
${ }^{5}$ Cabe mencionar que Alexiévich nació en 1948 en la URSS, en el terreno de la actual Ucrania, y a pesar de vivir en Bielorrusia escribe sus libros en ruso, siendo esta - tal y como ha manifestado en varias ocasiones- la lengua del imperio de que le interesa describir y desmitificar.
} 
La narración creada por Alexiévich confirma muchos de los conceptos relacionados con el género, la guerra y sus consecuencias (creo que en cierto grado con cualquier guerra dondequiera que ocurra): se concentra en las mujeres, sus recuerdos y emociones, desenmascarando así la insuficiencia de la literatura de la Segunda Guerra Mundial dominada por las voces masculinas y otras que se inscriben dentro del poder ejercido sobre las políticas de las emociones. Dicho de otra manera, la lectura de La guerra no tiene rostro de mujer deja entender que las narraciones histórico-literarias sobre los acontecimientos de la Segunda Guerra Mundial vislumbran su insuficiencia y manipulaciones mientras la historia del protagonismo femenino es silenciada. La autora centra su atención en los recuerdos personales, íntimos de las soldados, confeccionando unas secuencias temáticas de las voces femeninas que hacen memoria: "No escribo sobre la guerra, sino sobre el ser humano en la guerra. No escribo la historia de la guerra, sino la historia de los sentimientos" (Alexiévich, 2015, pos. 155). La estructura formal de su narración es bastante parecida en la obra de Tomasa Cuevas, basada en la transcripción y preparación (selección y organización) del material anteriormente registrado en un centenar de entrevistas con sus compañeras de activismo y de la prisión. Cuevas, sin embargo, además de hacer comentarios e introducir informaciones sobre las mujeres que narran su historia, deja su propio testimonio del activismo, la resistencia y la represión franquista, siendo ella también testigo directo de los sucesos. Alexiévich y Chacón pertenecen, en cambio, a la generación de postmemoria (Hirsch, 2012). Su perspectiva hacia los recuerdos mediados y narrados se caracteriza, pues, por un lado, por el desplazamiento que oscila entre la continuidad y la ruptura en lo subjetivo e imaginario de la experiencia "post", y por otro, por la mediación plasmada a través de la inversión, proyección y creación imaginativas (Hirsch, 2012, pp. 5-6). Estas estrategias postmemoriales reciben en nuestras autoras soluciones formales diferentes: en Alexiévich se trata de un reportaje literario polifónico, mientras Chacón optó por la forma novelesca, muy popular para las postgeneraciones en España. En su narración nos enteramos formalmente de las fuentes orales gracias al paratexto colocado al final de la novela donde la autora enumera a las personas que le "han regalado su historia" y, de hecho, los lectores pueden identificar varias historias de las protagonistas novelescas con las experiencias reales de unas resistentes y presas concretas de la cárcel de Las Ventas. Aunque se trata de una diferencia formal muy importante, ya que en el caso de la escritora extremeña tenemos que ver con la ficcionalización de las voces y las historias femeninas, al pensar en comparar los tres textos, es cabal el proceso de preparación de La voz dormida, y no solo la novela misma con su propia expresión poética. De ahí que me parezca oportuno resaltar, siguiendo a E. Portela, que el epígrafe de la primera parte de la novela (centrada en la cárcel femenina) son unas estrofas del poemario Amapola y memoria de Paul Celan (1952, el mismo que incluye el famoso "Todesfuge" o "Fuga de la muerte") "referidas a la imposición del silencio" (Portela, 2007, p. 53). Dulce Chacón, 
inspirada evidentemente por Celan y su insistencia en la ruptura del enmudecimiento después del Holocausto, se empeña en recobrar la lengua y el discurso, interrumpir el silencio y recuperar "las voces" que otorgan el título a la novela.

La forma final en que conocemos el texto de Alexiévich hoy en día tardó muchos años hasta ser publicada. La escritora trabajó en la versión final entre 1978 y 2004. La primera versión, después de esperar varios años hasta encontar una editorial interesada, fue publicada en las vísperas de perestroika, en 1985. No obstante, en 2002, Alexiévich se puso a reescribir el texto, aumentándolo con el material reunido en la época de transformación, dando cuenta a los lectores de que el carnaval de la libertad que se vivió en aquel tiempo en Rusia facilitó a sus protagonistas ampliar y añadir otros matices a sus historias. En la segunda versión, que salió en 2004, están incluidos algunos fragmentos de la propia autocensura de la autora, así como la argumentación de los censores que habían influido en la demora de la publicación del libro. Reproduzco un fragmento de la conversación con dos intervenciones del censor:

- Después de leer un libro como este, nadie querrá ir a la guerra. Usted con su primitivo naturalismo está humillando a las mujeres. A la mujer heroína. La destrona. Hace de ella una mujer corriente. Una hembra. Y nosotros las tenemos por santas. [...]

- ¿De dónde ha sacado usted esas ideas? Esas ideas no son nuestras. No son soviéticas. (Alexiévich, 2015, pos. 343 y 348)

La autora bielorrusa, al incorporar en la segunda edición los fragmentos anteriormente excluidos, hace bien patente que la circulación e influencia del objeto de las emociones que Sara Ahmed considera centrales para su estudio, está sometida a unas tensiones personales y sociales al mismo tiempo. No son solamente los objetos de emociones los que circulan, sino que los cuerpos en que estas emociones se generan, deambulan y transitan reaccionan al compás de su funcionamiento. De este modo la economía social (y política) del miedo visualiza unas dinámicas del poder.

Aunque el relato de la escritora bielorrusa está protagonizado por las mujeres rusas, soviéticas que no perdieron la guerra, sino que pertenecieron al ejército de la Victoria sobre el fascismo, su opinión crítica tiene varios puntos en común con lo que conocemos del ámbito español. En la introducción, al explicar la necesidad de emprender la temática de la mujer en la guerra, hay un fragmento que, al mismo tiempo, puede ser leído como un diálogo no-intencional frente a las disputas vigentes en España acerca de la memoria, la escritura y el género:

A lo largo de dos años, más que hacer entrevistas y tomar notas, he estado pensando. Leyendo. ¿De qué hablará mi libro? Un libro más sobre la guerra... ¿Para qué? Ha habido miles de guerras, grandes y pequeñas, conocidas y desconocidas. Y los libros que hablan de las guerras son incontables. Sin embargo... siempre han sido hombres escribiendo sobre hombres [...]. En lo que narran las mujeres no hay, o casi no hay, lo que estamos 
acostumbrados a leer y a escuchar: cómo unas personas matan a otras de forma heroica y finalmente vencen. O cómo son derrotadas. O qué técnica se usó y qué generales había. Los relatos de las mujeres son diferentes y hablan de otras cosas. La guerra femenina tiene sus colores, sus olores, su iluminación y su espacio. Tiene sus propias palabras. En esta guerra no hay héroes ni hazañas increíbles, tan solo hay seres humanos involucrados en una tarea inhumana. En esta guerra no solo sufren las personas, sino la tierra, los pájaros, los árboles. Todos los que habitan este planeta junto a nosotros. Y sufren en silencio, lo cual es aún más terrible. [...] Su guerra sigue siendo desconocida... Yo quiero escribir la historia de esta guerra. La historia de las mujeres. (Alexiévich, 2015, pos. 65-82)

Dulce Chacón insistía en varias entrevistas que, entre las mujeres cuyas memorias grababa al preparar la fase documental para su novela, había algunas que todavía a comienzos del siglo XXI no se sentían lo suficientemente cómodas para recordar y hablar de sus experiencias carcelarias. Su novela empieza con una escena en la madrileña cárcel de Las Ventas a través de la descripción de una de las protagonistas, de "La mujer que iba a morir [y que] se llamaba Hortensia" (Chacón, 2012, p. 11). Hortensia gracias a sus quehaceres diarios en la prisión intenta vencer el miedo, sin darse cuenta todavía de que, dentro de pocos meses, el tribunal sumarísimo de guerra la va a condenar a la muerte por fusilamiento, que será ejecutado en las tapias del Cementerio de Este: "El miedo de las mujeres que compartían la costumbre de hablar en voz baja. El miedo en sus voces. Y el miedo en sus ojos huidizos, para no ver la sangre. Para no ver el miedo, huidizo también, en los ojos de sus familiares" (Chacón, 2012, p. 12). Tras unas regulaciones legislativas introducidas al final de la guerra y en los primeros años de la dictadura, ${ }^{6}$ la penalización de mujeres fue masiva. No solo las cárceles estaban llenas de presas activistas y desafectas al régimen, sino que se abrieron y habilitaron como prisiones varios establecimientos en el territorio de todo el país: monasterios, castillos, escuelas, hospitales, balnearios, etc. Miles de mujeres pasaron por las cárceles franquistas, sufrieron una violencia sexual y de género, psicológica, simbólica (sobre todo ideológica y religiosa), como también la apropiación por parte del Estado de sus niños. Muchas de ellas nunca regresaron. La violencia, la victimización y la estigmatización tocó también a las mujeres de la retaguardia y de las afueras del sistema penitenciario. Por tanto, el miedo a romper la tranquilidad y estabilidad construidas después de la guerra fue comprensible. Sin embrago, entre las mujeres que lograron salir de las cárceles, hubo también algunas que continuaron su activismo después de ganar la libertad y que también se sintieron capaces de compartir sus historias. Todas ellas — según vemos claramente en relatos elaborados

\footnotetext{
${ }^{6}$ Se trata sobre todo de la Ley de Responsabilidades Políticas de 13 de febrero de 1939 (véase BOE, en http://www.boe.es/datos/pdfs/BOE//1939/044/A00824-00847.pdf) y la Ley sobre la Represión de la Masonería y del Comunismo de 1 de marzo de 1940 (véase BOE, en http://www.boe.es/datos/ pdfs/BOE//1939/044/A00824-00847.pdf).
} 
por Tomasa Cuevas así como en las novelas de otras ex presas (por ejemplo Mercedes Núñez o Juana Doña) — han subrayado no solamente su trauma sino su doble exlusión de la vida y del discurso vigentes: como perdedoras de la guerra y como mujeres a quienes el régimen excluyó de la actividad social, cultual y política.

Vuelvo al texto de Alexiévich. La autora bielorrusa demuestra a través de las narraciones de las mujeres que el discurso cultural está influido por el dogmatismo patriarcal. No solo al nivel lingüístico sino también simbólico y emocional. De ahí que, al ayudar a manifestarse a las voces y emociones femeninas, invita a las mujeres a manejar su trauma y, al mismo tiempo, como explica Aleksandra Zywert (2015, pp. 146-147), les deja la oportunidad de estar psíquicamente preparadas para afrontar su vida actual. Este tema está también muy presente en las mujeres que dejan su testimonio a Tomasa Cuevas. Es importante subrayar que ambas autoras permiten hablar a las mujeres que no escriben en el sentido tradicional del oficio, y que por sí mismas no hubieran emprendido la tarea de redacción du sus recuerdos. Un ejemplo muy simbólico, en este caso, es el relato de María del Carmen Cuesta que, emocionada después de ver la película de Truffaut, Farenheit 451, se quedó con la imagen de las personas disidentes del régimen convertidas en libros vivos:

Yo [...] pensé que éramos cientos, más que cientos, miles de mujeres que, como en esa película guardábamos también en nuestras mentes unos profundos testimonios: unos testimonios que también esperábamos confiadamente que pudieran salir en un momento determinado, y poder llenar todas las páginas de la historia, de esa historia que fue la época más larga, más negra y más brutal de nuestro país: la historia del fascismo. (Cuevas, 1985, p. 178)

La ruptura de los falsos mitos del poder llevada a cabo por la escritora bielorrusa abarca también las cuestiones de control dentro del ejército soviético en tareas consideradas normalmente masculinas (y viriles). Mientras el estatus oficial concedía en el ejército igual trato y derecho a los hombres y a las mujeres, en la práctica las mujeres sufrieron mucha más agresión y opresión: estuvieron inscritas en el territorio masculino sin llegar a ser jamás iguales, desde la falta de los medios de la higiene relacionada con su biología, hasta la manipulación en las estructuras jerárquicas. Devinieron víctimas de género tanto en la esfera oficial, como en la privada. Esta situación prevaleció, y de forma más amplia, todavía después de la guerra. La propaganda oficial se servía con predilección de la imagen de la mujer-soldado, pero en realidad esta imagen fue creada con objetivos sugestivo-persuasivos, en que no se incluía ni su verdadero papel, ni la perspectiva femenina de la guerra, con sus vivencias y sus emociones. Se visualizaba, por ende, una imagen exenta del verdadero contenido. Tal situación causó otro problema emocional, y sigo a Zywert (2015, p. 149-150): la autoaceptación de las mujeres, cuestión frecuentemente reiterada en la narración. Las veteranas, de hecho, no se adecuaban a ninguna visión del mundo, incluso la suya, porque las experiencias del combate se superponían en sus 
cualidades femeninas de, por ejemplo, futuras madres y esposas. Como resultado, fuertes y frágiles al mismo tiempo, devinieron víctimas de dos guerras, la Segunda Mundial y la personal, siendo la última un combate realizado a solas para buscarse un lugar en la sociedad de postguerra. Como efecto de esta marginación, las mujeres no podían contar con ser escuchadas, entendidas, ni ayudadas; es más, perdieron la seguridad humana que aportan los vínculos sociales, conducidas a una destructiva soledad tanto física como psíquica.

Los patrones culturales y estereotipados de la imagen de la mujer en la sociedad fueron una de las causas de su discriminación sobre todo después de la Segunda Guerra Mundial. Se solía creer que las mujeres habían ido a la guerra para pasarlo bien con los hombres. Este punto de vista fue compartido tanto por hombres como por mujeres, también dentro de las propias familias. Citaré dos testimonios reproducidos por Alexiévich:

Acabé la guerra en Berlín... Regresé a mi aldea con dos Órdenes de la Gloria y varias medallas. Estuve en casa tres días; al cuarto día, de madrugada, mientras todos dormían, mi madre me despertó: "Hijita, te he preparado tus cosas. Vete... Vete... Tienes dos hermanas pequeñas. ¿Quién querrá casarse con ellas? Todos saben que has pasado cuatro años en el frente, con los hombres...". Deje en paz a mi alma. Haga como los demás, escriba sobre mis condecoraciones... (Alexiévich, 2015, pos. 440-444)

¡Cómo nos recibió la Patria! No puedo contarlo sin llorar... Han pasado cuarenta años, pero incluso ahora me arden las mejillas. Los hombres no abrían la boca y las mujeres... nos gritaban: “iSabemos lo que estuvisteis haciendo allí! Os insinuasteis a nuestros hombres con vuestros chochos jóvenes. Sois las putas del frente... Perras militares...". Los insultos no faltaban, el ruso es rico... (Alexiévich, 2015, pos. 4132-4134)

Como bien ha observado Aleksandra Zywert (2015), a pesar de la emancipación promovida por la propaganda soviética, la mujer, de hecho, no tenía mucha más posibilidad que seguir el mismo camino trazado hace tiempo: su destino y obligación era ser obediente, tranquila, lista para estar dedicada a los otros y, sobre todo, ser esposa, madre y guardiana del hogar. Alexiévich demuestra gracias a su narración que hasta la perestroika la situación de las veteranas no cambió, y que nadie había estado interesado en escuchar a las "ciudadanas de segunda categoría" (Zywert, 2015, p. 152). De hecho, se creó una gran y tristísima paradoja: el discurso sobre la victoriosa guerra era omnipresente, la guerra afectó directamente a todas (o casi todas) familias soviéticas; sin embargo, la "gran" narración oficial quedó incompleta y censurada. La voz de las mujeres o fue suprimida y silenciada, u obligada a copiar los modelos masculinos de los acontecimientos, dentro de los cuales no hubo lugar, tampoco, para hablar de toda una variedad de sentimientos, entre ellas las de las madres.

Si me he atenido a los aspectos anteriormente mencionados en la obra de la escritora bielorrusa, sin por supuesto agotar el tema, es porque creo que presentan un 
parentesco, en sus marcos generales, con las lecturas de Tomasa Cuevas y Dulce Chacón. El dolor, el sufrimiento y el miedo se generan, habitan y transitan entre los cuerpos sometidos a diferentes archivos de poder hegemónico; sin embargo, y a pesar de dichas variedades, producen unos disturbios y molestias que provocan una negociación por parte del poder que desemboca en unos resultados parecidos de soluciones estructurales de su control y dominio. Las mujeres que dejan sus recuerdos a las autoras españolas cuentan la resistencia al franquismo y la represión ocurrida durante y después de la Guerra Civil. Su represión, como ya se ha subrayado, ha sido masiva. Sufrieron no solamente las activistas y combatientes, sino también madres, esposas, parejas, hermanas e hijas de los y las combatientes. En sus testimonios hay un ritmo de repetición sobre todo relacionado con la tortura, fusilamientos de sus compañeras, la penosa situación de las presas y de los niños que estaban en las cárceles con sus madres, así como la diaria vida carcelaria a través de la cual intentaban sostener su resistencia, la solidaridad, como también guardar su individualismo. Esos relatos desenmascaran el poder oficial llevado por parte del Estado franquista que concierne el discurso de la Gloriosa Victoria en varios niveles, pero la más ostensible es la denuncia del discurso oficial penitenciario relacionado con el programa de la "higiene mental de posguerra" (Vallejo Nágera, 1939, p. 247) y la "política racial" (Vallejo Nágera, 1937, p. 116). De ahí que la opresión carcelaria de las mujeres corresponda, como sostiene Ricard Vinyes, no al patrón foucaultiano de vigilancia y castigo, sino a doblegamiento y transformación (2003, p. 156). El modelo del presidio femenino fue basado en el esquema patriarcal de la sociedad, fundado sobre la base de la unión del Estado con la Iglesia y la asimetría de género. La política del franquismo hacia las mujeres se basaba en la marginalización y el control tanto social como moral. Por ende, las mujeres sufrían un rigor de encerramiento mucho más estricto, no podían redimir las condenas gracias al trabajo y los únicos abandonos de los muros carcelarios estaban relacionados con la celebración de las fiestas religiosas. La situación específica de las mujeres presas consistía también en que, con frecuencia, entraban en las cárceles con sus niños o daban a luz siendo presas. Muchas perdían a sus hijos por hambre y enfermedades infecciosas, como también por la apropiación por parte del Estado que en adelante los educaba en la ideología opuesta a sus convicciones y/o les dejaba en adopción a las familias adictas al régimen. ${ }^{7}$

\footnotetext{
${ }^{7}$ Estos datos sobre el presidio femenino del franquismo proceden del Patronato de San Pablo, institución creada a mediados de 1943 por el Ministerio de Justicia para encargarse de los hijos de los reclusos, que asumió la anterior labor al respecto del Auxilio Social y del Patronato de Nuestra Señora de la Merced. Así que "en 1942 estaban tutelados por el Estado en las escuelas religiosas y establecimientos públicos 9.050 niños con sus padres o madres en la cárcel. Al año siguiente, el número [...] ascendió a 12.042" (Vinyes, Armengou \& Belis, 2003, p. 59). Sin embargo, hay que destacar que no había un censo especial de los niños ingresados en las cárceles con sus madres,
} 
Las mencionadas peculiaridades relacionadas con el presidio femenino pasaron desgraciadamente desapercibidas durante muchos años dentro del discurso disidente del régimen que recuperaba la información sobre la opresión franquista. Hubo una negligencia en darse cuenta de las peculiaridades de las cáreceles de mujeres y las formas de violencia a que estas fueron sometidas. A pesar de visibilizar los orígenes de tal situación en la rivalidad con la actividad política de las mujeres, que apuntaría, como en el caso de las mujeres rusas, a los falsos mitos de igualdad en el activismo entre los géneros, Giuliana di Febo observó que aún en los mejores trabajos historiográficos de los años setenta, es decir, en la etapa preinicial de la transformación española, estaba vigente no solo en España sino en toda Europa la preferencia por los personajes femeninos excelentes. Es decir, "el protagonismo femenino era emblematizado y 'rescatado' por las biografías ejemplares de Dolores Ibárruri y Federica Montseny” (Di Febo, 2006, p. 157), mientras se mantenía la estructura jerárquica entre los géneros y el grueso de las mujeres resistentes se quedaba en la sombra, adscrito a los roles tradicionales del apoyo moral y espiritual a la lucha de los hombres. Para el caso del universo carcelario, yo añadiría indispensablemente a Matilde Landa, cuya trágica historia de suicidio en la cárcel de Palma de Mallorca, cometido para abstenerse del bautizo impuesto por las Monjas de la Caridad (regentes de aquel establecimiento penitenciario), fue utilizado como propaganda por el Partido Comunista Clandestino, inscribiéndola inmediatamente en el panteón de los mártires (Ginard i Ferón, 2005, p. 205). No obstante, el discurso oficial tanto partidista como de los investigadores del tema de las represiones del franquismo, tardó mucho más en darse cuenta de que el ejemplo de Matilde Landa podía abrir un verdadero debate acerca del fenómeno y de la especificidad del presidio femenino. Este trabajo tuvo que esperar a que lo hicieran las mismas expresas.

El historiador y biógrafo de Matilde Landa indica que hay una triste lógica entre las formas de violencia a que fueron sometidas las mujeres y la invisibilidad de la mujer como sujeto histórico y social (2013, p. 23). Desde la perspectiva que he tomado en este artículo, me convencería más agüir que los relatos del pasado, a pesar de fijar la memoria, apuntan a los principios de intelección. A lo mejor, para poder realizar esta crítica era necesaria una transformación que tuvo lugar dentro de los marcos de los estudios de la memoria para abrazarse con los estudios de género y también de las emociones. Marianne Hirsch en su investigación sobre la generación de postmemoria hace patente que: "gender, as sexual difference, can fulfill a number of functions in the work of memory. [...] And even when gender seems to be erased or invisible, feminist and queer readings can illuminate [...] how stories are told and images are created" (2012, p. 18). El trabajo para desmarginalizar la

los cuales, al superar la edad de tres años, eran desalojados y arrebatados. El único registro carcelario sobre ellos era el de los que pasaban por las enfermerías. 
memoria queer de las guerras y observar otras estrategias del poder sigue siendo todavía un reto.

Ahora bien, para Sara Ahmed, los afectos no tienen un carácter estático, por eso, es necesario investigar sus prácticas de dinamismo, cómo funcionan y qué es lo que hacen: tal y como precisa Labanyi (2016, en línea), no solamente entre los humanos, sino también entre las cosas, entre lo orgánico y lo no orgánico. A su vez Ahmed, dentro de su línea de pensamiento, insiste en que las emociones son y actúan en un tiempo que no se limita al tiempo de una vida individual: pueden mantener vivas las historias del pasado, como también abrirse al futuro, ya que gracias a su carácter dinámico y circulatorio "implican diferentes orientaciones hacia los otros" (2015, p. 304).

En la conferencia pronunciada en el CCCB, Jo Labanyi invitada por el Centre Dona i Literatura de la Universidad de Barcelona, explicó que "La teoría del afecto empieza de proponerse en el momento de emergencia de nuevas propuestas políticas basadas no en el individualismo, sino en opciones comunitarias [...]. El afecto no es una propiedad del yo, sino una reacción producida como relación del individuo con el mundo" (2016, en línea). Siguiendo entonces esta coordenada, me permito terminar repitiendo las palabras de Svetlana Alexiévich, citadas en forma de paratexto al comienzo del artículo, que considero como mi lema afectivo para el presente trabajo. Confío en que seamos capaces de ir reorientando la discusión sobre la memoria hacia un amplio repertorio de lecturas minuciosas, y de esta manera, tal vez, contribuir a una circulación de emociones pacifistas, también en las relaciones post-humanas: "No estaría mal escribir un libro sobre la guerra que provocara náuseas, que lograra que la sola idea de la guerra diera asco. Que pareciera de locos. Que hiciera vomitar a los generales..." (Alexiévich, 2015, pos. 179-189). 


\section{BIBLIOGRAFÍA}

Ahmed, S. (2015). Las políticas culturales de las emociones. México: UNAM.

Alexiévich, S. (2015). La guerra no tiene rostro de mujer. Penguin Random House, Grupo Editorial España. Kindle Edition.

- (2015, 10 diciembre). Нобелевская лекиия Светланы Алексиевич, “О проигранной битве”. En The Official Web Site of the Nobel Prize, Recogido en: https://www.nobelprize.org/nobel_prizes/ literature/laureates/2015/alexievich-lecture_ry.html

Bojarska, K. (2015). "Pamięć szarpana afektywnie". En A. Lipszyc \& M. Zaleski, Ciała zdruzgotane, ciata oporne. Afektywne lektury XX wieku (pp. 194-218). Warszawa: Wydawnictwo Instytutu Badań Literackich PAN.

Chacón, D. (2012). La voz dormida. Madrid: Punto de lectura.

Colmeiro, J. F. (2008). "Re-collecting Women's Voices from Prison: the Hybridization of Memories in Dulce Chacón’s Novel La voz dormida”. Foro hispánico: Revista Hispánica de Flandes y Holanda, 31, 191-209.

Cuevas, T. (1985). Cárcel de mujeres (1939-1945). 2 vols. Madrid: Sirocco.

Di Febo, G. (2006). "Resistencias femeninas al franquismo. Para un estado de la cuestión". Cuadernos de Historia Contemporánea, 28, 153-168.

Ginard i Féron, D. (2013). "Represión y especificidad de género: en torno a la violencia política contra las mujeres en la España del primer franquismo". En M. Nash (Ed.), Represión, resistencias, memoria: mujeres bajo la dictadura franquista (pp. 23-36). Granada: Comares.

- (2005). Matilde Landa. De la Institución Libre de Enseñanza a las prisiones franquistas. Barcelona: Flor del Viento.

Hanish, C. (1969). “The Personal Is Political”. En Writings by Carol Hanish (Página personal). Recogido en: http://www.carolhanisch.org/CHwritings/PIP.html (20 marzo 2016).

Hirsch, M. (2012). The Generation of Postmemory. Writing and Visual Culture After the Holocaust. New York: Columbia University Press.

Labanyi, J. (2010). "Doing things. Emotion, Affect and Materiality". Journal of Spanish Cultural Studies, 11 (3-4), 223-233.

- (2016, 15 marzo). "Pensar los afectos" (Conferencia [grabación audiovisual]). Centre de Cultura Contemporània de Barcelona (CCCB). Recogido en: http://www.cccb.org/ca/multimedia/videos/ pensar-els-afectes/223394 (20 marzo 2016).

Leggott, S. (2015). Memory, War and Dictatorship in Recent Spanish Fiction by Women. Lewisburg: Bucknell University Press.

Mangini, S. (1996). Memories of Resistance. Women's Voices from the Spanish Civil War. New Haven London: Yale University Press.

Ostałowska L. (2011, 28 abril). "Wszyscy zdradzili wojenne kobiety. Rozmowa ze Swietłaną Aleksijewicz”. Gazeta Wyborcza. Recogido en: http://wyborcza.pl

Portela, E. (2007). "Hijos del silencio. Intertextualidad, paratextualidad y postmemoria en La voz dormida de dulce Chacón". Revista de Estudios Hispanicos, 41, 51-71.

Prieto, C. (2011). El Holocausto olvidado: guerra, masacre, pacto, olvido y recuperación de la memoria histórica española. Madrid: Pliegos.

Ramos, A. (2012). Memoria de las presas de Franco. Madrid: Huerga \& Fierro.

Servén Díez, C. (2015). "Dulce Chacón: el testimonio de una violencia indecible contra la mujer". En A. Calderón Puerta, K. Kumor \& K. Moszczyńska-Dürst (Eds.), ¿La voz dormida? Memoria y género en las literaturas hispánicas (pp. 105-123). Varsovia: Instituto de Estudios Ibéricos e Iberoamericanos de la Univeridad de Varsovia. 
Vallejo Nágera, A. (1939). La locura y la guerra. Psicopatología de la guerra española. Valladolid: Castellana.

- (1937). Eugenesia de la Hispanidad y regeneración de la raza. Burgos: Editorial Española.

Vinyes, R. (2003). "El universo penitenciario durante el franquismo". En C. Molinero, M. Sala \& J. Sobrequés (Eds.), Una inmensa prisión. Los campos de concentración y las prisiones durante la guerra civil y el franquismo (pp. 155-175). Barcelona: Crítica.

- (2012). Irredentas. Las presas políticas y sus hijos en las cárceles franquistas. Madrid: Planeta, Temas de Hoy.

Vinyes, R., Armengou M. \& Belis R. (2003). Los niños perdidos del franquismo. Barcelona: Debolsillo.

Zywert, A. (2015). "Śmierć i dziewczyna. Wojna nie ma w sobie nic z kobiety Swietłany Aleksijewicz".

En M. Grzywacz \& M. Okupnik (Eds.), Kobiety i/a doświadczenie wojny. 1914-1945 i później (pp. 143-155). Poznań: Wydawnictwo Naukowe Wydziału Nauk Społecznych UAM. 